\title{
A Case Study of Reliability and Performance of the Electric Power Distribution Station Based on Time between Failures
}

\author{
Adam Baharum, ${ }^{1}$ Faris Mahdi Alwan, ${ }^{1,2}$ and Saad Talib Hasson ${ }^{3}$ \\ ${ }^{1}$ School of Mathematical Sciences, University Sains Malaysia 11800, USM Penang, Malaysia \\ ${ }^{2}$ Statistics Department, College of Administration and Economics, Baghdad University, Baghdad, Iraq \\ ${ }^{3}$ Planning and Studies Department, University of Babylon, Babylon, Iraq \\ Correspondence should be addressed to Faris Mahdi Alwan; faris.or@gmail.com
}

Received 26 February 2013; Revised 20 July 2013; Accepted 29 July 2013

Academic Editor: Yingwei Zhang

Copyright (C) 2013 Adam Baharum et al. This is an open access article distributed under the Creative Commons Attribution License, which permits unrestricted use, distribution, and reproduction in any medium, provided the original work is properly cited.

\begin{abstract}
This paper presents an algorithm for estimating the performance of high-power station systems connected in series, parallel, and mixed series-parallel with collective factor failures caused by any part of the system equipment. Failures that occur frequently can induce a selective effect, which means that the failures generated from different equipment parts can cause failures in various subsets of the system elements. The objectives of this study are to increase the lifetime of the station and reduce sudden station failures. The case study data was collected from an electricity distribution company in Baghdad, Iraq. Data analysis was performed using the most valid distribution of the Weibull distribution with scale parameter $\alpha=1.3137$ and shape parameter $\beta=94.618$. Our analysis revealed that the reliability value decreased by $2.82 \%$ in 30 days. The highest critical value was obtained for components $\mathrm{T}_{1}, \mathrm{CBF}_{5}$, $\mathrm{CBF}_{7}, \mathrm{CBF}_{8}, \mathrm{CBF}_{9}$, and $\mathrm{CBF}_{10}$ and must be changed by a new item as soon as possible. We believe that the results of this research can be used for the maintenance of power systems models and preventive maintenance models for power systems.
\end{abstract}

\section{Introduction}

The terms high voltage and high power mean that the voltages of the electrical energy are high enough to inflict harm or death on living things. A high-power system model is a necessary factor in the prediction capability of the system to supply a sufficient amount of electric power required at any given time. High-power systems are very complex and require maintenance of major factors. Reliability is one of the important factors in the design, operation, and maintenance of electric power systems [1]. In 2004, Popova [2] studied the structure of Bayesian group replacement policies for a parallel system of $n$ items with exponential failure times and random failure parameter. In this paper, the researcher proved the sufficiency of optimally observing the system only at failure times in the case of two items operating in parallel. In a parallel system of $n$ items, the optimal structure of the Bayesian group replacement policies was presented by Popova when the failure times were distributed exponentially [2]. A system subjected to external and internal failures was considered by Montoro-Cazorla and Pérez-Ocón. The failures followed a Markovian arrival process, and the operational time has a phase-type distribution [3]. Marquez et al. presented a case study on a type M63 point machine at the Carillion Rail (formerly GTRM) Training Centre in Stafford (UK). They described the development of a condition monitoring system based on pattern recognition to detect and diagnose machine point failures. They used the data collected from a set of points under test and showed that potential failure modes can be successfully detected and diagnosed [4]. Castro and Sanjuán presented a combined maintenance strategy in which the repair of the system failure was performed only in an interval of time within the operating period. The aim of their work was to exhibit the optimal interval in which the repairs can be performed [5]. Kapur et al. [6] proposed a new software reliability growth model based on "Itô̄" type of stochastic differential equation. They considered an SDE-based generalized Erlang model with logistic error detection function. Zhang et al. [7] provided good monitoring performance by using kernel partial least squares (KPLS). They also proposed multiblock kernel partial least squares (MBKPLS) algorithm and proved that this method performs better when it is applied to large-scale processes since it combines the advantages of both KPLS and MBPLS by being applied to monitor 
large-scale processes. In 2011, Barbosa et al. conducted field surveys on compression splices with suppliers and users. They also suggested some procedures and inspection routines to improve system reliability in their field study in an electricity transmission system in Brazil [8]. The distribution and expected values for a $k$-out-of- $n$ system were studied by Eryilmaz. The " $k$-out-of- $n$ " is a system that has $n$ components and operates only if at least $k$ components are functioning [9]. The first to define the guiding parking reliability of urban parking variable message signs (VMSs) were Mei et al. [10]. They based the presentation of this problem by analysing the parking choice under guiding and optional parking lots and determining the guiding parking reliability of VMS by formulating a mathematical program for this reliability model. Yingwei et al. [11] proposed a method for the analysis of multimode batches. This method has a new scientific contribution by indicating that multimodes are separated correctly since the cross-mode correlations are considered and the common information is extracted, also that the expensive computing load is avoided since only the specific information is calculated when a mode is monitored online; after that, two different subspaces are separated, and the common and specific subspace models are built and analysed, respectively.

In the light of the above survey of related literature, the main goal of this paper is to find the optimal fitting for the failure data via time between failures (TBF). We determine the estimation of the parameters for all components for this station, as well as its reliability value. Furthermore, the current paper is the first to present this problem and its analysis; thus, the results are new and innovative.

\section{Failure Functions}

We assume that $T$ is a continuous random variable with values in a positive real line. Many methods are available to specify the properties of a random variable [12]. The best four methods specifying the properties of $T$ are probability density function (PDF), $f(t)$, cumulative distribution function (CDF), $F(t)$, reliability function $R(t)$, and hazard or failure function $h(t)$. These functions are called "failure functions" and can be described mathematically as

$$
\begin{gathered}
f_{T}(t, \alpha, \beta)=\frac{\beta}{\alpha}\left(\frac{t}{\alpha}\right)^{\beta-1} \exp \left(-\left(\frac{t}{\alpha}\right)^{\beta}\right), \quad t>0, \alpha, \beta>0 \\
F(t)=1-\exp \left(-\left(\frac{t}{\alpha}\right)^{\beta}\right) \\
R(t)=\exp \left(-\left(\frac{t}{\alpha}\right)^{\beta}\right) \\
h(t)=\frac{\beta}{\alpha}\left(\frac{t}{\alpha}\right)^{\beta-1}, \quad t \geq 0, \alpha>0, \beta>0
\end{gathered}
$$

where $\alpha$ and $\beta$ are called the scale and shape parameters, respectively [12].

The reliability function is one of the mathematical and engineering indicators that describe the role of the equipment in the system using the probability function [13]. Reliability is defined by the North American Reliability Council Glossary of Terms as "The degree of performance of the elements of the bulk electric system that results in electricity being delivered to customers within accepted standards, and in the amount desired" $[14,15]$. Reliability can be calculated from the frequency, duration, and magnitude of the adverse effects by the equipment on the electric supply. Electric system reliability can be addressed by considering two basic and functional aspects of the electrical system: adequacy and security [14]. Competition arises among manufacturing companies, especially within the warranty period, by increasing this period based on product quality. Reliability is an important element to measure product specifications. Furthermore, ensuring reliability reduces the cost of corrective actions on items that fail within the warranty period [16]. From this definition of reliability, we can see that reliability analysis involves the analysis of binary outcome $(0,1)$ (i.e., success $=1$ and failure data $=0)[12]$.

\section{Problem Statement}

The current paper studies and analyses the TBF of the station transformers that transform electricity from $33 \mathrm{KV}$ to $11 \mathrm{KV}$, denoted as $33 / 11 \mathrm{KV}$. The power station under this case study included three power transformers. Each transformer had a circuit breaker with limited capacities (1,200 A), denoted as $\mathrm{CBT}_{i}$, that functions as the main circuit breaker of the transformer, where $i$ is the number of transformers 1,2 , and 3. The transformers are connected to the communication bus between them (termed as Bus-Bar in this paper), which is linked with a group of feeders to each of the transformers. Transformers 1,2, and 3 are separated in the Bus-Bar by circuit breakers with limited capacities of $800 \mathrm{~A}$, called the BusBar circuit breakers (CBB). Each feeder has a circuit breaker with a capacity of $400 \mathrm{~A}\left(\mathrm{CBF}_{i}\right)$, where $i$ represents the number of the feeders (10 feeders). The main circuit breaker must be switched ON, and the Bus-Bar circuit breaker must be switched OFF if the transformers are operating. However, if one of these transformers fails for any reason, the CBT must be switched OFF and the $\mathrm{CBB}$ is switched $\mathrm{ON}$ to provide electricity to the failed transformer feeders. For a more detailed treatment of the station operation, the readers are referred to Alwan et al. [13,17].

\section{Methodology}

The main focus of the current paper is on the performance of a station component that fails randomly; that is, the TBF is a random variable [13]. In this case, a statistical function to identify the statistical distribution of the TBF is studied by running the distribution fitting software "EasyFit." Data for TBFs was collected from an electricity distribution company in Baghdad, Iraq. The study period was five years. We visited the maintenance department and met the technicians and engineers. The head technician explained the nature of the work at the stations from the engineering point of view. This is shown in Table 1. The first column in Table 1 represents failures numbers, and the second column mentions the number of days required for the station to fail. For example, the first TBF value was calculated between 12 am on 1 January 
TABLE 1: Time between failures of the electric power distribution station for five years.

\begin{tabular}{lc}
\hline Failure number & TBFs (day) \\
\hline 1 & 187.833333 \\
2 & 118.9166667 \\
3 & 133.8854167 \\
4 & 48.9895833 \\
5 & 97.8854167 \\
6 & 57.9583333 \\
7 & 561 \\
8 & 38.8854167 \\
9 & 81.9166667 \\
10 & 21.83333 \\
11 & 90.8854167 \\
12 & 15.79166667 \\
\hline
\end{tabular}

and 18:00 pm on 6 Jul. Accordingly, the first step down occurred after 187.833333 days. We studied the reliability of these stations and found the optimal method for their maintenance. The stations also needed further study and analysis because of the difficult conditions and the shortage in electric power in Iraq. After several days of meetings, technical notes were organized, and the workers shared their experiences in repairing these stations. That helped further our understanding of the issues at hand. The data were analysed and tested under several distributions using the "EasyFit" software, and through the optimal analysis of the data, it was found that it follows the Weibull distribution with scale parameter $\alpha=1.3137$ and shape parameter $\beta=94.618$.

A goodness of fit for this statistical distribution was tested, including the use of the Kolmogorov-Smirnov, AndersonDarling, and Chi-square tests. The idea behind the goodnessof-fit tests is to have the "distance" critical values measured between the data and the distribution being tested. Then, that critical value is compared to some threshold value. The goodness-of-fit reports includes the test statistics and the critical values calculated for various significance levels $(\alpha=$ $0.2,0.1,0.05,0.02,0.01)$. The histogram was based on sample data (TBFs). Defining the number of vertical bars was based on the total number of observations. The equation $Q=$ $1+\log 2 N$ was used where $N$ is the total number of TBFs and $Q$ is the resulting number of classes. The height of each histogram bar indicates how many data points fall into that class. Obviously, the distribution with the lowest statistical value is the best-fitting model. The critical values can be extra useful when the null hypothesis is rejected at all selected significance levels, and it was required to know at which level it could be accepted. Figure 1 shows the quality of fits for nine distributions. The fitting result of TBFs histogram with the Weibull distribution is shown in Figure 2 while Figure 3 shows the PDF function of Weibull distribution $(\alpha=1.3137$ and $\beta=94.618)$. For a more detailed treatment of the fitting method, the readers are referred to Alwan et al. [18].

The reliability function for a Weibull random variable is given in (3). The reliability block diagram for the system in the current case study is shown in Figure 4 which shows a visual

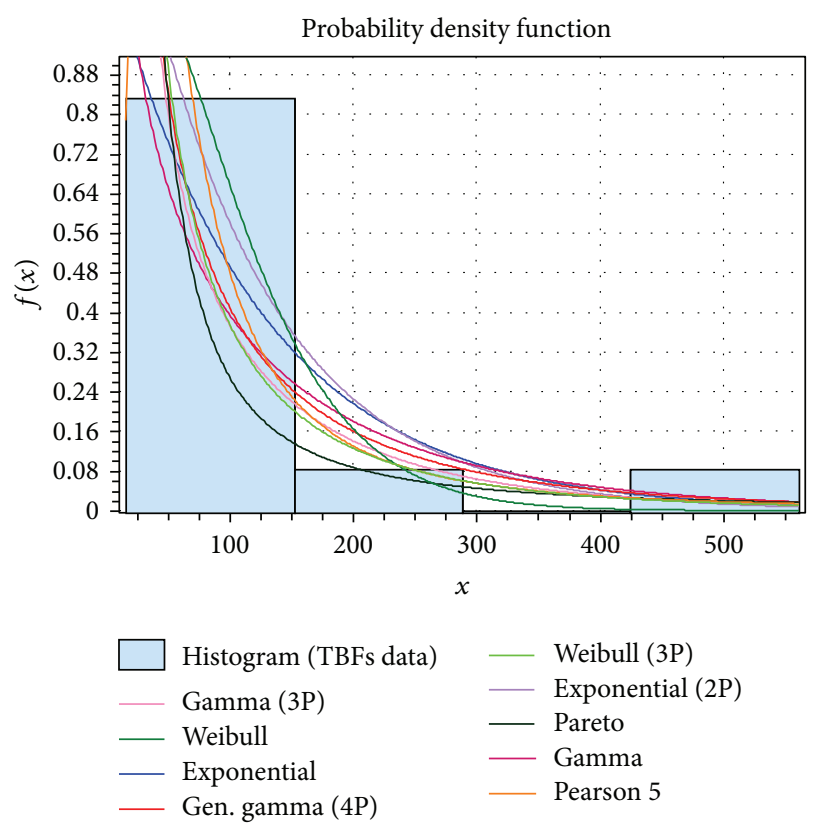

FIGURE 1: The fitting result for nine distributions of TBFs histogram.

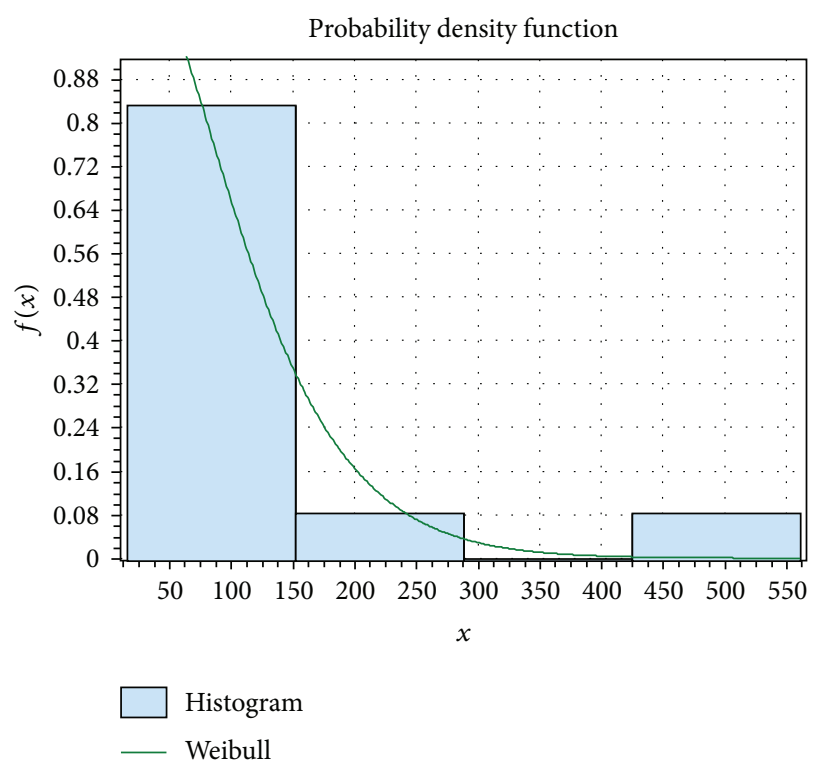

FIGURE 2: The result of Weibull distribution fit with TBFs data histogram.

representation of how the components are configured to form a working system. From Section 3, the CBB does not function if and only if one of the transformers does not operate. A total of 16 different components exist, excluding the CBB.

We can classify the block diagram for the station system shown in Figure 4 as follows.

(i) Transformers group:

$$
R_{\mathrm{TG}}(t)=1-\prod_{i=1}^{3}\left(1-R_{\mathrm{T} i}(t) \times R_{\mathrm{CBT} i}(t)\right),
$$




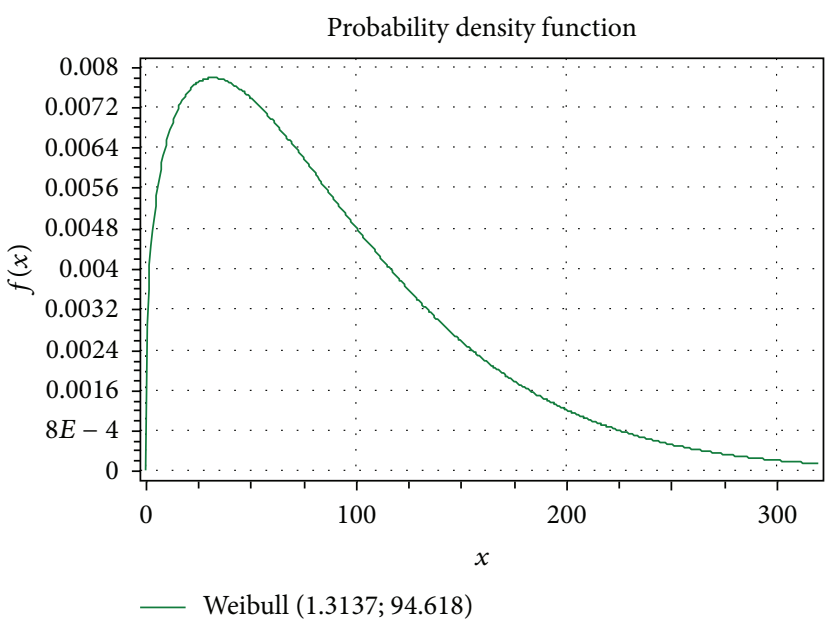

FIGURE 3: The PDF functions of TBFs data of a Weibull random variable with $\alpha=1.3137$ and $\beta=94.618$.

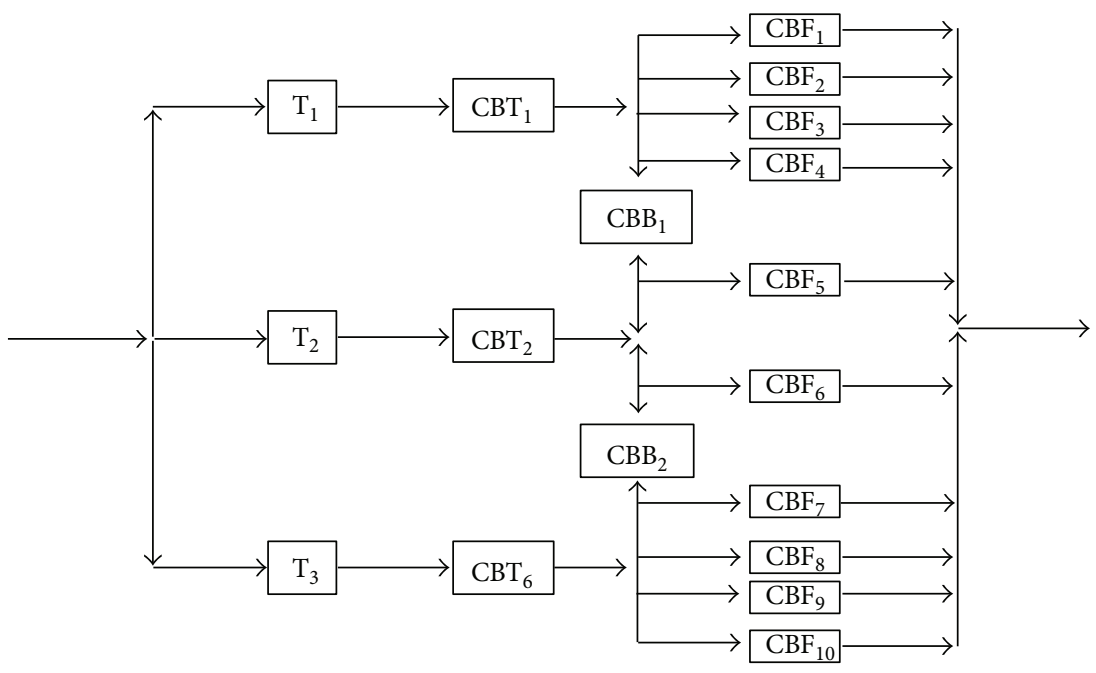

Figure 4: The 33/11 KV electric power distribution station mixed system.

where $R_{\mathrm{T}}$ is the reliability of transformers 1,2 , and 3 and $R_{\mathrm{CBT}}$ is the reliability of the main circuit breaker of transformers 1, 2, and 3 .

(ii) Feeders group:

$$
R_{\mathrm{FG}}(t)=1-\prod_{i=1}^{10}\left(1-R_{\mathrm{Fi}}(t)\right)
$$

where $R_{\mathrm{F}}$ is the reliability of feeders 1 to 10 .

(iii) System reliability:

$$
R_{\mathrm{SYS}}(t)=R_{\mathrm{TG}}(t) \times R_{\mathrm{FG}}(t)
$$

\section{Weibayes Analysis and Shape Parameter Value}

Several analysis methods are available for a large sample of data. However, the analysis of a small or very small sample constrained the engineers/researchers to use the Weibull or Weibayes analysis [19]. The Weibull or Weibayes analysis can describe the model's failure that is previously unknown. Furthermore, it can be used for the goodness of fit of the behavioural data for a given distribution by analysing the shape parameter value [20]. This process is shown in Figure 5, which can be distinguished from general forms depending on the $\beta$ value, as discussed in [20]:

$0<\beta<1$ indicates a decreasing failure rate,

$\beta=1$ indicates that the distribution approaches an exponential distribution, and the failure rate is constant;

$1<\beta<2$ indicates an increasing failure rate (IFR) in the form of a concave curve;

$\beta=2$ indicates a special case where the failure rate is linear, and the distribution takes the form of the Rayleigh distribution for electronic; 


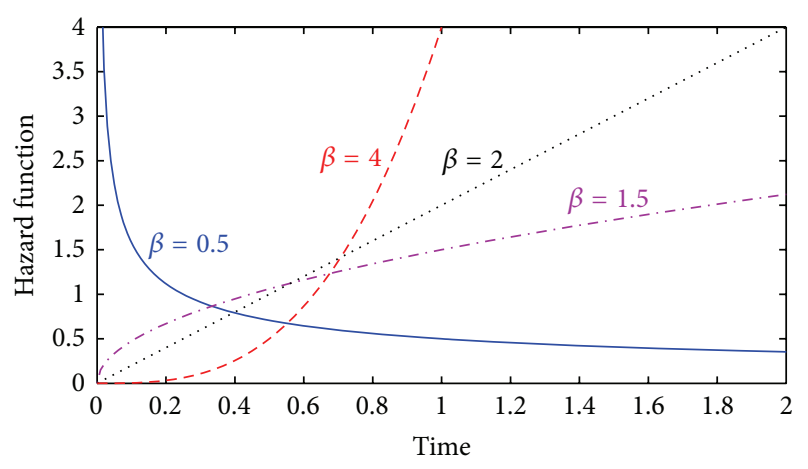

FIGURE 5: The effect of shape parameter value, $\beta$, on the Weibull hazard rate function.

$\beta>2$ indicates IFR in the form of a convex curve;

$3<\beta<4$ indicates IFR, and the distribution approachs normal distribution.

\section{System Reliability}

The Weibull distribution is the best analysis for the data TBF under many distributions using the "EasyFit" software. For a more detailed treatment of the fitting method, the readers are referred to Alwan et al. [18]. The maximum likelihood method is used to estimate the scale parameter $(\alpha)$ and shape parameter $(\beta)$ in the Weibull distribution. The maximum likelihood function of the Weibull distribution is seen as

$$
\begin{aligned}
\beta_{i+1}=\beta_{i}-\frac{(n / \beta)+\sum_{i=1}^{n}\left[\left(t_{i}\right) /\left[(1 / n) \sum_{i=1}^{n}\left(t_{i}\right)^{\beta}\right]^{1 / \beta}\right]}{-\left\{(n / \beta)+\sum_{i=1}^{n}\left[\left(\left(t_{i}\right)^{\beta} /\left((1 / n) \sum_{i=1}^{n}\left(t_{i}\right)^{\beta}\right)\right) \ln ^{2}\left(\left(t_{i}\right) /\left[(1 / n) \sum_{i=1}^{n}\left(t_{i}\right)^{\beta}\right]^{1 / \beta}\right)\right]\right\}} \\
-\frac{\sum_{i=1}^{n}\left[\left(t_{i}\right)^{\beta} /\left[(1 / n) \sum_{i=1}^{n}\left(t_{i}\right)^{\beta}\right]\right] \ln \left[\left(t_{i}\right) /\left[(1 / n) \sum_{i=1}^{n}\left(t_{i}\right)^{\beta}\right]^{1 / \beta}\right]}{-\left\{(n / \beta)+\sum_{i=1}^{n}\left[\left(\left(t_{i}\right)^{\beta} /\left((1 / n) \sum_{i=1}^{n}\left(t_{i}\right)^{\beta}\right)\right) \ln ^{2}\left(\left(t_{i}\right) /\left[(1 / n) \sum_{i=1}^{n}\left(t_{i}\right)^{\beta}\right]^{1 / \beta}\right)\right]\right\}}
\end{aligned}
$$

where $\alpha, \beta$, and $n$ are the scale parameter, shape parameter, and sample of size, respectively. For a more detailed treatment of the likelihood function, the readers are referred to Guure et al. [21]. Table 2 shows the estimated value of the scale and shape parameters of each compound.

The reliability of the station was calculated for the times imposed from $t=1$ to $t=30$, where $t$ is expressed in days, as shown in Table 3.

\section{Limitations of the Study and Future Work}

We assumed that the restrictions to this study were as follows.

(i) Major attention was concentrated inside the distribution station only with no focus on the source. It is to be noted that when the power distribution is in short supply (below $33 \mathrm{Kv}$ ), there is an increase in temperature of the transformers which leads to an abrupt step down of the electric power distribution station.

(ii) The same data has been made use of for 5 consecutive years.

(iii) EasyFit software was utilised in the study.

In this paper, we consider the electric power distribution station as an independent part. Supposing the data of failure rate $(\lambda)$ for individual components of the station was obtained and dealt with using the Markov model "Hidden SemiMarkov models," then improved performance of the power distribution station is expected. We are aware that Markov's model relies on the failures of the present state instead of considering the past data [22]. Our study could be used to examine preventive maintenance modelling in order to evaluate its effects on the components of the station. This could help in increasing the electricity supply and decreasing the operating cost of the power station.

\section{Conclusion}

The TBF has been analysed to find the best-fitting distribution. Using the distribution fitting software "EasyFit," we found that the most valid distribution is the Weibull distribution with scale parameter $\alpha=1.3137$ and shape parameter $\beta=94.618$. After estimating the scale and shape parameters of each component (16) using the maximum likelihood method, the reliability value for the system in the first day was 0.99 . However, if the station still operates on the 30th day, the reliability decreased to 0.97 . The reliability of the system that continues to operate decreased considerably (e.g., the reliability for 60 days is 0.91 and that for 120 days is 0.77 ). This result shows that parts of the station continuously deteriorate because of aging. Furthermore, using the Weibayes analysis for the $\beta$ value enabled us to conclude that the station fails or experiences IFR. The components $\mathrm{T}_{1}, \mathrm{CBF}_{5}, \mathrm{CBF}_{7}, \mathrm{CBF}_{8}$, 
TABLE 2: Scale and shape parameter value estimation for each compound.

\begin{tabular}{lcc}
\hline Compounds & $\widehat{\alpha}$ & $\widehat{\beta}$ \\
\hline $\mathrm{T}_{1}$ & 454.79 & 2.72 \\
$\mathrm{~T}_{2}$ & 454.79 & 0.718 \\
$\mathrm{~T}_{3}$ & 454.79 & 0.718 \\
$\mathrm{CBT}_{1}$ & 202.38 & 0.63 \\
$\mathrm{CBT}_{2}$ & 202.38 & 0.63 \\
$\mathrm{CBT}_{3}$ & 219.1 & 0.76 \\
$\mathrm{CBF}_{1}$ & 313.17 & 0.787 \\
$\mathrm{CBF}_{2}$ & 191.254 & 0.721 \\
$\mathrm{CBF}_{3}$ & 326.145 & 1.793 \\
$\mathrm{CBF}_{4}$ & 261.67 & 1.2 \\
$\mathrm{CBF}_{5}$ & 425.309 & 2.88 \\
$\mathrm{CBF}_{6}$ & 464.731 & 1.422 \\
$\mathrm{CBF}_{7}, \mathrm{CBF}_{8}, \mathrm{CBF}_{9}, \mathrm{CBF}_{10}$ & 449.18 & 2.99 \\
\hline
\end{tabular}

TABLE 3: Estimated reliability values of the station for 30 days.

\begin{tabular}{lccc}
\hline$T$ (day) & $\widehat{R}_{\text {SYS }}$ & $T$ (day) & $\widehat{R}_{\text {SYS }}$ \\
\hline 1 & 0.999954003 & 2 & 0.999818754 \\
3 & 0.999598937 & 4 & 0.999298779 \\
5 & 0.998922077 & 6 & 0.998472283 \\
7 & 0.997952567 & 8 & 0.997365866 \\
9 & 0.99671491 & 10 & 0.996002256 \\
11 & 0.995230305 & 12 & 0.99440132 \\
13 & 0.993517438 & 14 & 0.992580685 \\
15 & 0.991592984 & 16 & 0.990556163 \\
17 & 0.989471964 & 18 & 0.988342051 \\
19 & 0.987168011 & 20 & 0.985951362 \\
21 & 0.98469356 & 22 & 0.983395999 \\
23 & 0.982060016 & 24 & 0.980686895 \\
25 & 0.979277872 & 26 & 0.977834133 \\
27 & 0.976356821 & 28 & 0.974847035 \\
29 & 0.973305837 & 30 & 0.971734246 \\
\hline
\end{tabular}

$\mathrm{CBF}_{9}$, and $\mathrm{CBF}_{10}$ had the highest critical value and must be changed by a new item as soon as possible.

\section{References}

[1] R. Billinton and R. N. Allan, Reliability Evaluation of Power Systems, Plenum Press, New York, NY, USA, 2nd edition, 1996.

[2] E. Popova, "Basic optimality results for Bayesian group replacement policies," Operations Research Letters, vol. 32, no. 3, pp. 283-287, 2004.

[3] D. Montoro-Cazorla and R. Pérez-Ocón, "Reliability of a system under two types of failures using a Markovian arrival process," Operations Research Letters, vol. 34, no. 5, pp. 525-530, 2006.

[4] F. P. G. Marquez, P. Weston, and C. Roberts, "Failure analysis and diagnostics for railway trackside equipment," Engineering Failure Analysis, vol. 14, no. 8, pp. 1411-1426, 2007.

[5] I. T. Castro and E. L. Sanjuán, "An optimal maintenance policy for repairable systems with delayed repairs," Operations Research Letters, vol. 36, no. 5, pp. 561-564, 2008.
[6] P. K. Kapur, S. Anand, S. Yamada, and V. S. S. Yadavalli, "Stochastic differential equation-based flexible software reliability growth model," Mathematical Problems in Engineering, vol. 2009, Article ID 581383, 15 pages, 2009.

[7] Y. Zhang, H. Zhou, S. J. Qin, and T. Chai, "Decentralized fault diagnosis of large-scale processes using multiblock kernel partial least squares," IEEE Transactions on Industrial Informatics, vol. 6, no. 1, pp. 3-10, 2010.

[8] C. Barbosa, A. Francato, C. Mariotoni, I. Ferreira, N. Mascia, and P. Barbosa, "Analysis of critical field procedures for power HV overhead transmission line splices installed after restructuring of Brazilian electrical sector," Engineering Failure Analysis, vol. 18, no. 7, pp. 1842-1847, 2011.

[9] S. Erylmaz, "Dynamic behavior of k-out-of-n:G systems," Operations Research Letters, vol. 39, no. 2, pp. 155-159, 2011.

[10] Z. Mei, Y. Tian, and D. Li, "Analysis of parking reliability guidance of urban parking variable message sign system," Mathematical Problems in Engineering, vol. 2012, Article ID 128379, 11 pages, 2012.

[11] Z. Yingwei, C. Tianyou, L. Zhiming, and Y. Chunyu, "Modeling and monitoring of dynamic processes," IEEE Transactions on Neural Networks and Learning Systems, vol. 23, no. 2, pp. 277284, 2012.

[12] M. S. Hamada, A. G. Wilson, C. S. Reese, and H. F. Martz, Bayesian Reliability, Springer Series in Statistics, Springer, New York, NY, USA, 2008.

[13] F. M. Alwan, A. Baharum, and S. T. Hasson, "Reliability and failure analysis for high power station based on operation time," in Proceedings of International Conference on Statistics in Science, Business, and Engineering (ICSSBE '12), pp. 370-373, Langkawi, Malaysia, 2012.

[14] P. A. Morris, R. Cedolin, and C. D. Feinstein, "Reliability of electric utility distribution systems," EPRI White Paper 1000424, 2000.

[15] G. Brunekreeft and T. McDaniel, "Policy uncertainty and supply adequacy in electric power markets," TILEC Discussion Paper, University of Tilburg, 2005.

[16] C. S. Aksezer, "Failure analysis and warranty modeling of used cars," Engineering Failure Analysis, vol. 18, no. 6, pp. 1520-1526, 2011.

[17] F. M. Alwan, A. Baharum, and S. T. Hasson, "The p.d.f fitting to time between failure for high power stations," Applied Mathematical Sciences, vol. 6, no. 125-128, pp. 6327-6339, 2012.

[18] F. M. Alwan, A. Baharum, and S. T. Hasson, "The performance of high power station based on time between failures (TBF)," Research Journal of Applied Sciences, Engineering and Technology, vol. 5, no. 13, pp. 3489-3498, 2013.

[19] R. B. Abernethy, The New Weibull Handbook: Reliability \& Statistical Analysis for Predicting Life, Safety, Survivability, Risk, Cost and Warranty Claims, Gulf Publishing, Houston, Tex, USA, 4th edition, 2003.

[20] C. E. Ebeling, An Introduction to Reliability and Maintainability Engineering, McGraw-Hill, Singapore, 1997.

[21] C. B. Guure, N. A. Ibrahim, and A. O. M. Ahmed, "Bayesian estimation of two-parameter Weibull distribution using extension of Jeffreys' prior information with three loss functions," Mathematical Problems in Engineering, vol. 2012, Article ID 589640, 13 pages, 2012.

[22] S.-Z. Yu, "Hidden semi-Markov models," Artificial Intelligence, vol. 174, no. 2, pp. 215-243, 2010. 


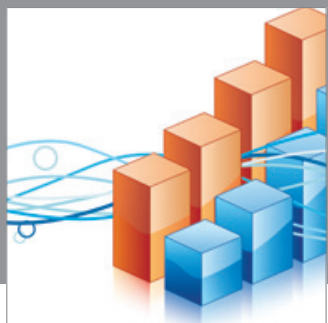

Advances in

Operations Research

mansans

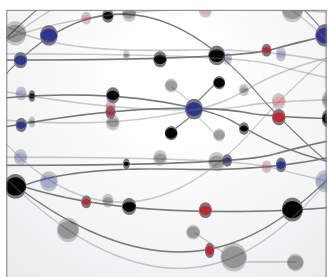

The Scientific World Journal
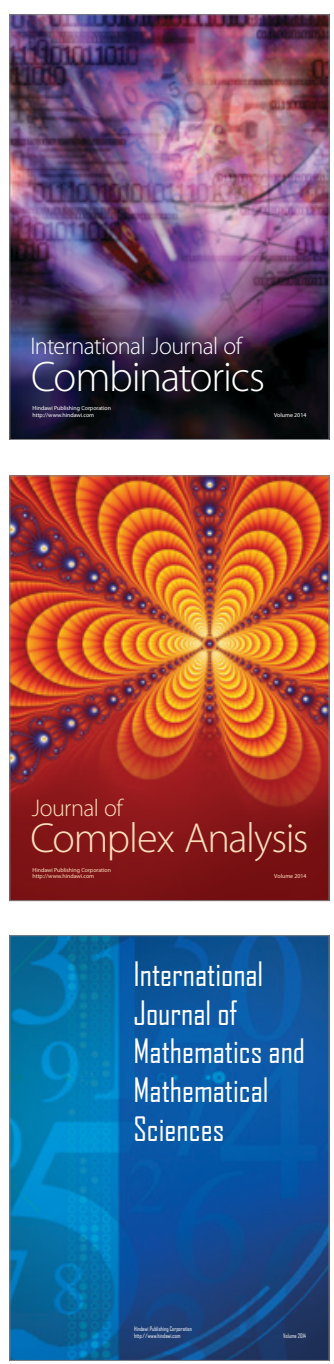
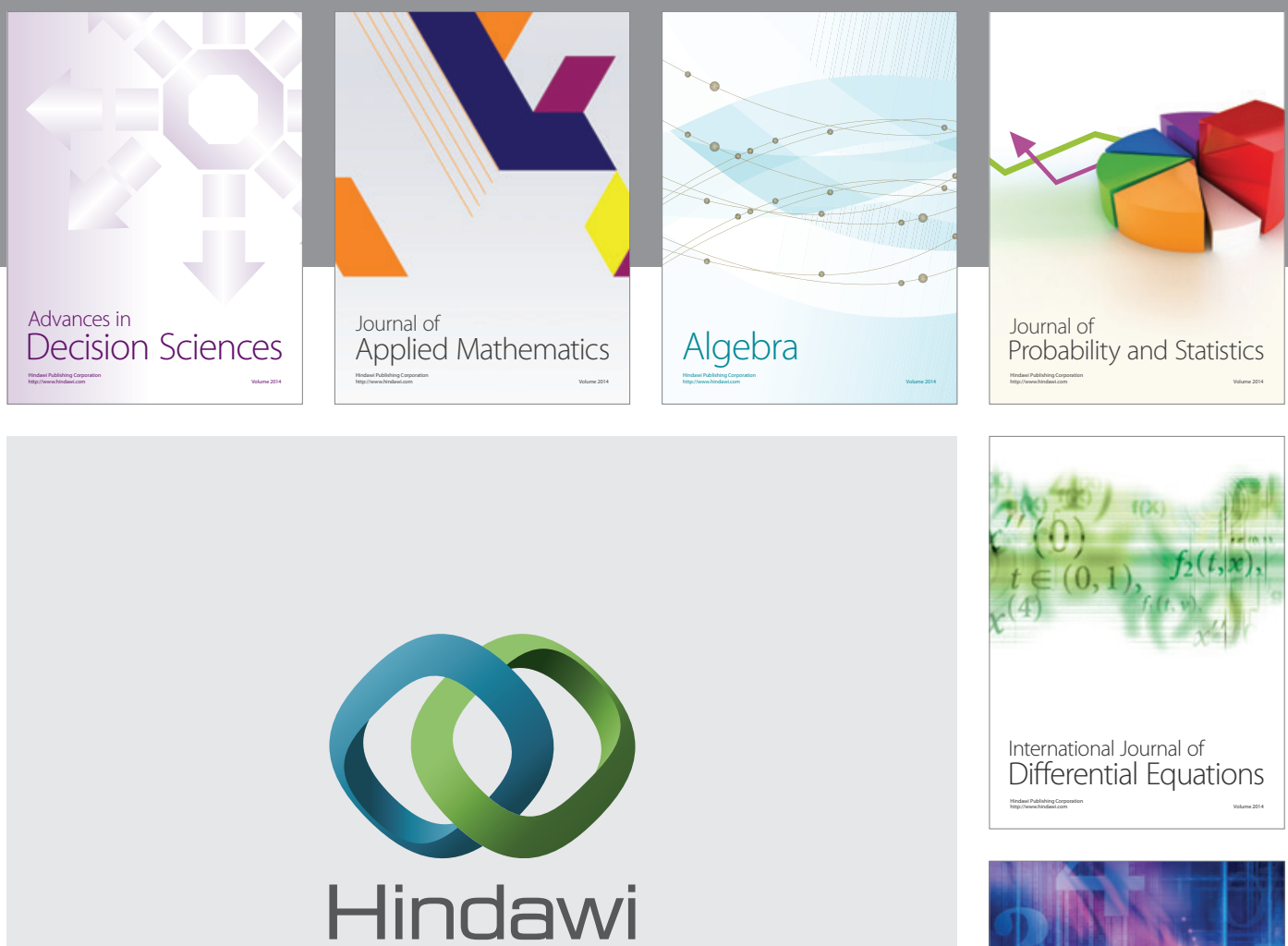

Submit your manuscripts at http://www.hindawi.com
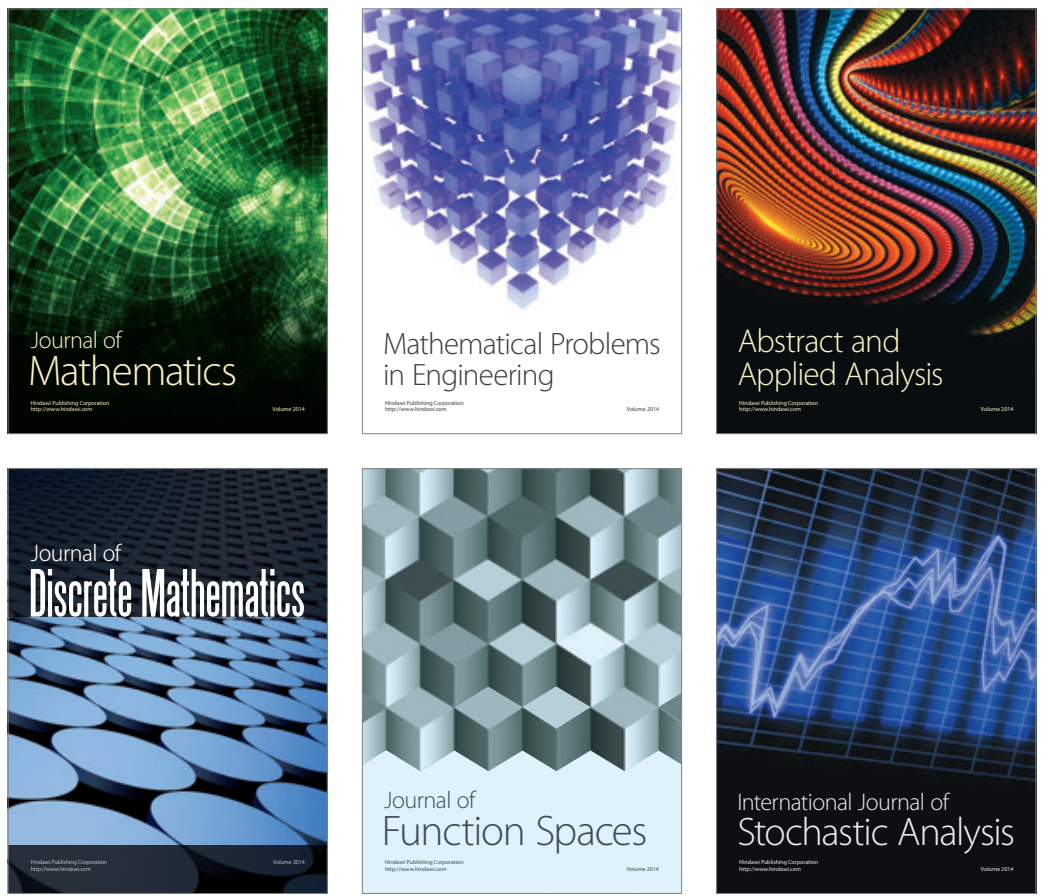

Journal of

Function Spaces

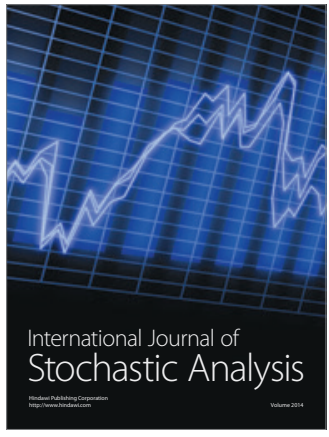

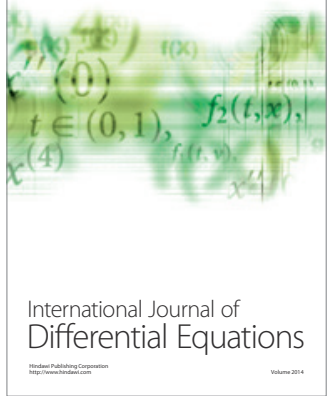
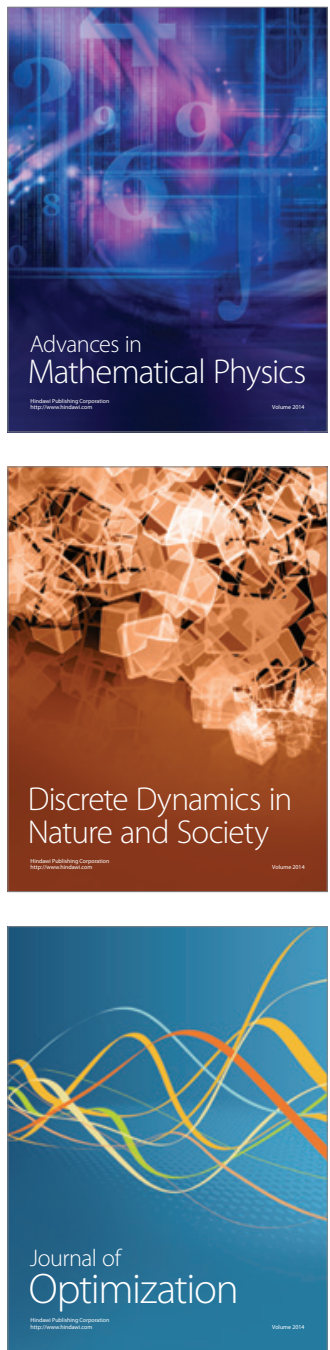